\title{
AN INVESTIGATION OF THE PSYCHIATRIC ASPECTS OF DISSEMINATED SCLEROSIS
}

\author{
BY \\ R. T. C. PRATT \\ From the Department for Nervous Diseases, the Middlesex Hospital, London
}

\begin{abstract}
Many investigations have been made of the psychiatric aspects of disseminated sclerosis, but there is little agreement on the findings or on their significance. In this paper a report is made of an investigation of 100 patients suffering from disseminated sclerosis and of 100 control patients, with regard to premorbid personality, emotional antecedents of the illness, and psychiatric emotional and intellectual changes following the illness.
\end{abstract}

\section{Previous Investigations}

Premorbid Personality.-A characteristic premorbid personality of hysterical type has been noted by some authors (Langworthy, 1950 ; Grinker, Ham, and Robbins, 1950). The majority of authors, however, do not consider the premorbid personality of importance. Charcot (1877) remarked of his male patients :

" These are, for the most part, persons who have lost caste, and who, thrown out of the general current, and too impressionable, are ill-provided with the means of maintaining what, in Darwin's theory, is called the 'struggle for life'", but Charcot concluded "in the pathological antecedents of the patients themselves we generally find nothing but vague indicia."

Neither Brain (1930) nor Wilson (1940) mentioned any characteristic premorbid personality.

Emotional Antecedents.-The earliest clinical account of disseminated sclerosis associated the onset of the disease with emotional stress. Augustus d'Este (Firth, 1948) wrote in his diary :

"I attended his funeral : there being many persons present I struggled violently not to weep. I was however unable to prevent myself from so doing. Shortly after the funeral .... my eyes were so attacked that when fixed upon minute objects indistinctness of vision was the consequence."

Charcot (1877) stated :

"The circumstances most commonly assigned as causes of this disease, by patients, appertain to the moral order-long-continued grief or vexation ... the aetiology is a somewhat trite one, such as may be met with again, as it were, at the beginning of all the chronic diseases of the nervous system."

Moxon (1875) gave a dramatic instance of the association of the onset of the disease with an emotional shock :

"She ascribed the commencement of her ailment ... to a shock received on the occasion of her sister's death in a confinement, by seeing the doctor come with hands covered with blood into the room, and being told her sister was dead .... At the time of the shock, she had at once a hysterical fit, and after this had weakness of the legs, which disappeared soon, but returned in six months."

There have been many other striking examples recorded of emotional stress antedating manifestations of the disease, but few adequate control observations have been recorded. Braceland and Giffin (1950), who studied 50 control patients, concluded that "the necessity and sufficiency of psychological trauma required to explain the genesis of these specific symptoms were not demonstrated in our cases".

The influence of emotion in causing a transient exacerbation of symptoms due to an established lesion was mentioned by Brickner and Simons (1950), who referred to two patients, but there has been little emphasis on this aspect of the disease.

Changes in Personality.-There is a divergence of opinion on changes during the course of the disease.

Psychiatric Changes.-Brown and Davis (1922) stated : "Apart from certain mood changes, for example euphoria, multiple sclerosis patients usually retain the same personality that they had before their illness began". Braceland and Giffin (1950) found changes dependent on the stage of the disease : in the early stage "the patient's reaction in the largest measure is determined by his mode of response to incapacity or dysfunction induced by any type of disease", whereas in the chronic stage " the individual now reacts with the classical signs of 
organic disease of the brain ". Hysterical symptoms have classically been associated with disseminated sclerosis. Wilson (1940), however, wrote : "At early periods fugitive symptoms may well give rise to a suspicion of hysteria, but genuine hysterical phenomena are distinctly rare, and their development a mere coincidence ".

Estimates vary of the incidence of psychosis in disseminated sclerosis ; psychotic manifestations in the disease are of no characteristic pattern (Ombredane, 1929; Langworthy, Kolb, and Androp, 1941).

Emotional Changes.-Most authors record as evidence of euphoria a statement by the patient that his mood is consistently cheerful. Others, without apparent inquiry of the patient, deduce his mood from his external appearance. The danger of this procedure is well shown in an extract from the diary of Barbellion (1948), a sufferer from the disease :

"I am astonished at the false impression these entries give of myself. The picture is incomplete anyhow. It represents the cloud of forebodings over my inner self, but does not show the outward front I present to others. This is one of almost constant gaiety-unforced and quite natural."

Other authors record a "relative euphoria," a contrast of this outward front with what they consider should be the patient's appropriate affective reaction; they thus introduce a further distortion into a record of mood changes. It is, therefore, not surprising that the diverse connotations given to the term euphoria have led to varying estimates of its frequency (Langworthy and others, 1941 ; Borberg and Zahle, 1946 ; Mackay, 1950 ; Brickner, 1950 ; Grinker, Ham, and Robbins, 1950). Braceland and Giffin (1950) examined 75 patients, and found euphoria in $10 \%$, depression in $20 \%$, lability of mood in $18 \%$, and an unusual degree of irritability in $12 \%$. They also found that " all patients who exhibited euphoria as their predominant mood gave evidence of widespread cerebral disease or disturbance". Their conclusions are of particular interest in that many of their cases were from the series of Cottrell and Wilson (1926), who found that 63 of 100 consecutive patients stated that their mood was consistently cheerful or happy, while in 10 it was consistently sad or unhappy.

Increase in lability of affect and decrease in control of the expression of emotion have both been noted, although at times the context does not allow of their differentiation. Charcot (1877) stated that " it is not rare to see these give way to foolish laughter for no cause, and sometimes, on the contrary, melt into tears without reason".
Moxon (1875) stated : “. . . one hears bursts of unmeaning laughter, and in conversation the patient will laugh incontinently where no soundminded person can find cause for merriment. Weeping is equally out of just relation to its proper cause". Cottrell and Wilson (1926) found that 95 of 100 cases showed " facility and amplification of emotional expression (affect)", (71 of these showing constant smiling or laughing), and that in 96 there had been a change in this respect since the illness began. The symptom was not always as evident to the patient as it was to the examiner, since only 87 reported an awareness of change in emotional expression. These authors also emphasized the finding that 84 patients admitted to "eutonia", a sense of physical well-being in striking contrast to their crippled physical state. They considered that change in mood, change in bodily feeling, and change in emotional expression and control constituted a diagnostic triad of greater value than any neurological symptom-complex, and postulated that it was due to dysfunction of the thalamus.

Intellectual Changes.-Clinical estimates of intellectual deterioration resulting from the disease have varied widely. Charcot (1877) stated : " there is marked enfeeblement of the memory : conceptions are formed slowly: the intellectual and emotional faculties are blunted in their totality". Moxon (1875) found enfeeblement of mind less frequently: "This is not forced upon the observer at all obviously in many cases; in others it is among the early and evident symptoms ". Ombredane (1929) found intellectual deterioration in 36 of 50 cases : in six the deterioration amounted to dementia. In contrast, Cottrell and Wilson (1926) stated : "After careful observation we were able to demonstrate in only two cases (out of 100), any signs of actual intellectual deterioration ".

Standardized intelligence tests have recently been used in an investigation by Canter (1951) of intellectual deterioration in disseminated sclerosis. The 47 patients in his series were a representative sample of the total population of World War II American veterans in the early stages of the disease (duration one to eight years, average four years). A direct estimate of intellectual deterioration was made in 23 patients whose scores on the Army General Classification test at entry into the armed forces were available and were compared with the scores at the time of the investigation. The mean loss over an average period of four years was highly significant, and indicated that intellectual deterioration had occurred in this group. A direct estimate of intellectual deterioration, over a shorter 
period of time, was made on 47 patients who were tested twice at an interval of six months with the Wechsler-Bellevue battery. When compared with healthy controls, this group showed a highly significant deterioration, even over this comparatively short time. Indirect estimates of intellectual deterioration depend on the finding that, when deterioration is present, vocabulary is maintained relatively intact, whereas performance on a variety of other tests is more severely impaired. Canter used four tests of this type : the Wechsler-Bellevue battery, the short form of the Babcock scale, the Shipley Hartford test, and the short form of the Hunt Minnesota test. Each of these tests revealed the presence of some intellectual deterioration in the group of 47 patients. Intellectual deterioration, as measured both by direct and indirect methods, increased with the neurological rating of degree of disability.

\section{Present Investigation}

Material and Method of Inquiry.-The patients with disseminated sclerosis (D.S.) were chosen at random from available patients with the disease attending the Department for Nervous Diseases, Middlesex Hospital ; these patients were however selected, in that inpatients, and to a greater extent outpatients, were as a rule not in the most advanced stage of the disease (Table I). This selection of the material would not give rise to inaccuracy in assessing the premorbid personality and the emotional antecedents of the disease, and might well render such assessment more accurate. However, changes in personality following the illness would tend to be less marked in such a series than in a series of patients with all stages of the disease evenly represented. Almost every patient knew the name and nature of his illness, and had had opportunity of meeting other patients with moderate or severe disability resulting from the disease.

TABLE I

DEGREE OF DISABILITY

\begin{tabular}{|c|c|c|c|c|}
\hline & & Severe & Moderate & Mild \\
\hline Male : & $\begin{array}{ll}\text { D.S. } & \cdots \\
\text { Control } & \ldots\end{array}$ & $\begin{array}{l}9 \\
5\end{array}$ & $\begin{array}{l}24 \\
15\end{array}$ & $\begin{array}{l}17 \\
30\end{array}$ \\
\hline Female : & $\begin{array}{ll}\text { D.S. } & \ldots \\
\text { Control } & \ldots\end{array}$ & $\begin{array}{l}9 \\
5\end{array}$ & $\begin{array}{l}15 \\
22\end{array}$ & $\begin{array}{l}26 \\
23\end{array}$ \\
\hline
\end{tabular}

Control patients were matched for sex and approximately for age at interview (Table II). All were patients of the Department for Nervous Diseases, Middlesex Hospital, and all save three were suffering from organic disease of the nervous system. The interview was accepted by the patient as an attempt to contribute further to the knowledge and management of his illness. It was considered that indifferent controls, for example patients admitted for repair of hernia, would be unlikely to be fully cooperative in an interview concerned largely with their personal life history. No patient was chosen as a control if the final primary diagnosis were one of psychoneurosis or of any disease widely considered at present to be psychosomatic in nature.

The interview took the form of a psychiatric inquiry into the patient's life history ; it was not rigidly standardized. The history of the patient's illness was taken separately, and was then correlated with the life history. Direct inquiry was later made into emotional stress antedating the onset and relapses of the disease, and into emotional and intellectual changes following on the disease. An intelligence test was performed by each patient.

Premorbid Personality.-There is no satisfying scheme of personality assessment. Nevertheless an attempt was made to assess the premorbid personality of each patient both as a whole and in more limited aspects. The assessment of personality as a whole was made in this series by allotting each patient to the appropriate class in the personality schemes of Jung (extraversion-introversion), and of Sheldon (viscerotonia, somatotonia, cerebrotonia). Jung (1928) described the introverted attitude as " hesitating, reflective, reticent ", the extraverted as characterized by " an accommodating and apparently open and ready disposition, at ease in any given situation ". Sheldon (Sheldon, Hartl, and McDermott, 1949) summarized the varieties of temperament as follows : "Viscerotonia is manifested by relaxation, conviviality, and gluttony for food, for company and for affection or social support"; "somatotonia is manifested by bodily assertiveness and by desire for muscular activity"; "cerebrotonia is manifested by (1) inhibition of both viscerotonic and somatotonic expression, (2) hyperattentionality or overconsciousness ". The numbers in each class did not differ significantly when patients with disseminated sclerosis were compared with the

TABLE II

AGE AT INTERVIEW AND NUMBER OF PATIENTS IN EACH AGE-GROUP

\begin{tabular}{|c|c|c|c|c|c|c|c|c|c|c|c|c|}
\hline Age at & $\begin{array}{l}\text { Interview } \\
\text { years) }\end{array}$ & $15-19$ & $20-24$ & $25-29$ & $30-34$ & $35-39$ & $40-44$ & $45-49$ & $50-54$ & $55-59$ & $60-64$ & Total \\
\hline Male : & $\begin{array}{l}\text { D.S. } \\
\text { Controls .. }\end{array}$ & $\overline{1}$ & $\begin{array}{l}2 \\
1\end{array}$ & $\begin{array}{l}6 \\
7\end{array}$ & $\begin{array}{l}6 \\
9\end{array}$ & $\begin{array}{r}11 \\
7\end{array}$ & $\begin{array}{l}14 \\
13\end{array}$ & $\begin{array}{l}6 \\
4\end{array}$ & $\begin{array}{l}2 \\
5\end{array}$ & $\begin{array}{l}1 \\
1\end{array}$ & $\begin{array}{l}2 \\
2\end{array}$ & $\begin{array}{l}50 \\
50\end{array}$ \\
\hline Female : & $\begin{array}{l}\text { D.S. } \ldots \\
\text { Controls . }\end{array}$ & $\begin{array}{l}1 \\
1\end{array}$ & $\begin{array}{l}3 \\
3\end{array}$ & $\begin{array}{l}7 \\
8\end{array}$ & $\begin{array}{r}11 \\
8\end{array}$ & $\begin{array}{r}13 \\
9\end{array}$ & $\begin{array}{r}5 \\
11\end{array}$ & $\begin{array}{l}7 \\
6\end{array}$ & $\begin{array}{l}2 \\
3\end{array}$ & $\begin{array}{l}1 \\
1\end{array}$ & - & $\begin{array}{l}50 \\
50\end{array}$ \\
\hline
\end{tabular}


control patients. In addition the patients with disseminated sclerosis did not appear as a group to be of any other characteristic personality type or types.

Limited aspects of the personality were investigated by recording the presence or absence of the following features: (1) the occurrence of somatic symptoms (for example headache, abdominal pain) following emotional stress; (2) hysterical manifestations*; (3) obsessional traits ; (4) obsessional neurosis $\dagger ;$; (5) depressive episode ; (6) marked degree of psychopathy ; (7) physiological instability in childhood $\ddagger ;$ (8) the patient's statement that he was of a worrying temperament (Table III).

TABLE III

Premorbid Personality

\begin{tabular}{|c|c|c|c|c|c|c|c|c|}
\hline & 1 & 2 & 3 & 4 & 5 & 6 & 7 & 8 \\
\hline $\begin{array}{r}\text { Male : D.S. } \ldots \\
\text { Controls } \ldots\end{array}$ & $\begin{array}{r}9 \\
12\end{array}$ & $\begin{array}{l}2 \\
3\end{array}$ & $\begin{array}{l}10 \\
12\end{array}$ & $-\overline{1}$ & $\underline{2}$ & $\begin{array}{l}3 \\
1\end{array}$ & $\begin{array}{l}13 \\
10\end{array}$ & $\begin{array}{l}21 \\
17\end{array}$ \\
\hline $\begin{array}{c}\text { Female : D.S. } \\
\text { Controls }\end{array}$ & $\begin{array}{l}24 \\
17\end{array}$ & $\begin{array}{l}2 \\
2\end{array}$ & $\begin{array}{l}9 \\
7\end{array}$ & $\begin{array}{l}3 \\
2\end{array}$ & $\begin{array}{l}1 \\
5\end{array}$ & 1 & $\begin{array}{r}3 \\
13\end{array}$ & $\begin{array}{l}29 \\
26\end{array}$ \\
\hline
\end{tabular}

Score-see text.

to tell stories about a series of pictures presented to him ; underlying tendencies which the patient will not or cannot admit are expressed in the content of the stories. Since only two patients revealed aggressive tendencies in their stories, results in the small group tested do not suggest that unexpressed aggression plays a part in the genesis of disseminated sclerosis.

Emotional Antecedents. - If emotional disturbances at a conscious level are of significance in bringing on the onset or relapse of disseminated sclerosis, such disturbances ought to be encountered more frequently before an attack of the disease in patients with disseminated sclerosis than in a control series of patients. The occurrence of an emotional disturbance at stated intervals before the onset of the disease, and the occurrence of such a disturbance for a prolonged period up to and including the time of onset, are recorded in Table IV. When the totals are compared it is found that in 38 patients with disseminated sclerosis and in 26 control patients emotional stress antedated the onset of the disease ; this difference however does not quite reach the level of significance $(\chi=1 \cdot 8 *$ ).

TABLE IV

NUMBER OF PATIENTS (D.S.) AND CONTROLS (C.) WITH EMOTIONAL STRESS AT STATED INTERVALS BEFORE THE ONSET AND RELAPSES OF THEIR DISEASE

\begin{tabular}{ll|c|c|c|c|c|c|c|c|c}
\hline \multicolumn{1}{c|}{ Sex } & Group & $\begin{array}{c}\text { No. of Onsets (O) } \\
\text { or Relapses (R) }\end{array}$ & Minute & Hour & Day & Week & Month & $\begin{array}{c}\text { Prolonged } \\
\text { Strain }\end{array}$ & Total \\
\hline Male &. & D.S. & O 50 & - & - & 1 & - & 3 & 15 & 19 \\
Male &. & C. & O 50 & - & - & - & - & 2 & 8 & 10 \\
Female &. & D.S. & O 50 & - & - & 1 & 1 & 3 & 14 & 19 \\
Female &. & C. & O 50 & - & - & - & -1 & 3 & 13 & 17 \\
Male &. & D.S. & R 90. & - & - & - & 13 & 3 & 18 & 41 \\
Female &. & D.S. & R 139 & - & 2 & 3 & 10 & 8 \\
\hline
\end{tabular}

The numbers in each category did not differ significantly when patients with disseminated sclerosis were compared with controls. The patients with disseminated sclerosis and the control patients were also compared in respect of good or bad environment in childhood, and of separation from father or from mother before the age of 15 . No significant differences were found.

It has been postulated that psychosomatic disorders are due to a lack of discharge of affect through conscious channels, and in particular that unexpressed aggression may play a predominant role in this respect. Fifteen patients with disseminated sclerosis were given the Thematic Apperception Test (Murray, 1943). This test requires the subject

* Including amnesia, blepharospasm, globus, neurasthenia, functional overlay, labour pains in a man, vomiting, and aphonia

$\dagger$ Including phobias, ruminations, and hypochondriasis

† Sleep-walking, stammering, and bed-wetting
The tendency in patients with disseminated sclerosis for antecedent emotional stress to be reported, especially by those in whom somatic symptoms follow emotional stress, and by those of a worrying temperament, did not reach the level of significance $(\chi=1.0$ and 1.6 respectively). In the three instances of the onset of disseminated sclerosis within a week of an emotional stress, this was not of unusual degree or significance to the patient concerned, and was therefore considered unlikely to be of aetiological significance. The number of instances of emotional disturbance antedating relapses in patients with disseminated sclerosis is recorded in the same table ; the figure of $25 \%$ is very similar to that obtained for the onset of the disease in control patients $(26 \%)$ and suggests that emotional stress played no part in determining relapses of the disease.

\footnotetext{
* $\chi$, to be significant at the $5 \%$ level, must be $2 \cdot 0$ or greater.
} 
In a few instances, however, an emotional stress appears to have precipitated the onset or relapse of disseminated sclerosis. Two instances from this series, and a further six instances, selected from a larger series of 840 patients attending the Middlesex Hospital, are given below.

Case No. 80. Relapse.-Aged 39, one hour after receiving a letter containing bad news, she went out on her usual bicycle ride. She was only just able to return, and has not walked since that date.

Case No. 84. Relapse.-Aged 16 she had a severe quarrel one night with the daughter of her mother by adoption. The quarrel continued the next morning. One hour later an attack of vertigo and vomiting began.

Onset.-“N.W.J., in April, 1934, when aged 21, sustained a through and through wound of the right foot as a result of jumping on a nail. The wound was dressed, and he stayed away from work for two weeks. In July of the same year, while riding his motorcycle with his fiancée on the pillion seat, he rounded a corner at an excessive speed and had a narrow escape from a head-on collision with a car. At once his legs felt numb, 'as if the blood had drained from them'. He proceeded on his way, but for the next 10 minutes he had considerable difficulty in keeping his feet on the foot-rests. Within an hour the legs felt normal. He attributed the loss of feeling in his legs to the mental shock which he experienced. Seven days later his legs felt tired and numb and he tended to drag the right one". (McAlpine, 1946).

Onset.-C.P., aged 20 , had a violent quarrel with his fiancée and broke off the engagement. In the middle of that night he was violently sick, and when he awoke in the morning the right arm and leg were useless.

Relapse.-J.W., aged 20, in 1940, during an air-raid, found she was unable to run to a shelter. When in the shelter she noticed tingling in her fingers and toes on flexing her neck.

Relapse.-C.F., aged 32, was restraining a hemiplegic patient when he had a further stroke. She walked quickly away for assistance, and almost immediately had a sensation of something bubbling down her spine ; her legs became stiff and weak, and remained so for four months.
Relapse.-E.M., aged 41, was unaffected by news of his mother's death from a stroke. Aged 42, on hearing of his father's death from a stroke, his walking became worse within a few hours, without improvement over the following three years.

Relapse.-H.B., aged 28 (during a progressive attack of weakness of the legs). Her little girl, who was pushing her doll's pram up and down the pavement outside the house, walked away and would not return when called. The patient became very anxious, but eventually her husband heard her cries and fetched the child. When the patient turned to go indoors she noticed a marked increase in the weakness of her legs, lasting for 10 days.

In these instances the association in time between the emotional stress and the onset or relapse of the disease is so striking that it is difficult to believe that it is purely coincidental.

It is necessary to approach the relationship between emotion and an attack of the disease from the opposite angle, and to examine the number of patients in whom a severe emotional stress at least once was not followed within a month by the onset or relapse of the disease. The relevant figures (Table V) show that such stress frequently is not followed by a bout of the disease.

Certain patients find that occasionally or invariably emotional disturbances, often of a specific kind, lead after a characieristic time-interval to an exacerbation of symptoms of a pre-existing lesion (Table VI). There is a significant difference $(\chi=2.8)$ between the number of patients with disseminated sclerosis (18) and the number of

TABLE $\mathrm{V}$

NUMBER OF PATIENTS WITH SEVERE EMOTIONAL STRESS NOT FOLLOWED WITHIN ONE MONTH BY ONSET OR RELAPSE OF THE DISEASE

\begin{tabular}{c|c|c|cc}
\hline Sex & Group & $\begin{array}{c}\text { Number } \\
\text { at Risk }\end{array}$ & $\begin{array}{c}\text { Before } \\
\text { Onset }\end{array}$ & $\begin{array}{c}\text { After } \\
\text { Onset }\end{array}$ \\
\hline Male & D.S. & 50 & 16 & 7 \\
Male & Control & 50 & 23 & 7 \\
Female & D.S. & 50 & 18 & 13 \\
Female & Control & 50 & 23 & 8 \\
\hline
\end{tabular}

TABLE VI

EXACERBATION OF SYMPTOMS BY EMOTION

\begin{tabular}{|c|c|c|c|c|c|c|c|c|c|c|c|c|}
\hline \multirow{3}{*}{ Sex } & \multirow{3}{*}{ Group } & \multirow{3}{*}{$\begin{array}{l}\text { Number } \\
\text { at Risk }\end{array}$} & \multicolumn{5}{|c|}{ A. Invariably } & \multicolumn{5}{|c|}{ B. Occasionally } \\
\hline & & & \multicolumn{5}{|c|}{ Time Interval } & \multicolumn{5}{|c|}{ Time Interval } \\
\hline & & & Minute & Hour & Day & Week & Month & Minute & Hour & Day & Week & Month \\
\hline $\begin{array}{l}\text { Male } \\
\text { Male } \\
\text { Female } \\
\text { Female }\end{array}$ & $\begin{array}{l}\text { D.S. } \\
\text { Control } \\
\text { D.S. } \\
\text { Control }\end{array}$ & $\begin{array}{l}50 \\
47 \\
50 \\
50\end{array}$ & $\begin{array}{r}10 \\
2 \\
8 \\
3\end{array}$ & $\begin{array}{l}\overline{1} \\
3 \\
3\end{array}$ & $\frac{-}{1}$ & $\begin{array}{l}- \\
-\end{array}$ & $\frac{1}{-}$ & $\frac{6}{1}$ & $\overline{-}$ & $\begin{array}{l}-1 \\
2 \\
2\end{array}$ & $\begin{array}{l}- \\
- \\
-\end{array}$ & $\begin{array}{l}- \\
-\end{array}$ \\
\hline
\end{tabular}


controls (5) who state that a certain emotional stimulus leads invariably within the lapse of a minute to an exacerbation of symptoms. There is a tendency which does not reach the level of significance $(\chi=1.6)$ for patients who describe themselves as "worriers" to suffer from these exacerbations ; there is no association, however, between the previous tendency for emotional stress to result in somatic symptoms and the exacerbation of a symptom of disseminated sclerosis by emotional stress. The following cases exhibited this exacerbation of symptoms.

Case 5.-Worry led to increase in unsteadiness.

Case 10.-Weakness of right hand and leg affected by any emotional stress-"anything not capable of a logical solution ".

Case 21.-Any form of anger led to increase of weakness of the left leg.

Case 23.--"Walking definitely worse when worrying about hospital or when self-conscious."

Case 27.-Anxiety led to tremor of the leg.

Case 28. - If really upset, sight and walking were affected within seconds.

Case 31.-Whenever frightened or quarrelling legs became weak for up to three hours.

Case 39.- - When I get nervy, numbness and weakness affect my right side."

Case 43.-Worries, especially self-consciousness, led to increase in weakness of the legs.

Case 45.-Blurring of vision became definitely worse when self-conscious, less so when worried, and was unaffected by anger.

Case 56.- - If pushed for time I get harassed, and my right leg is affected."

Case 57.-Emotional upset led to increase in numbness of the right leg lasting at times up to 24 hours.

Case 62.-Whenever " worked up " she got an immediate stiffening feeling in the legs; she was able to do the same things, but had to make a greater effort.

Case 68.-On being insulted, picked up a chair to strike someone: "The chair had just reached the height of my shoulders when the strength left my arms and I dropped it. My legs were weak and I had to sit down."

Case 70.-Extract from a letter, June 1944: “The present bombing is upsetting my nerves more than ever, and walking in consequence is dreadful. Immediately the alert sounds, so my legs stiffen."

Case 75.-When "strung-up", legs affected for a minute or so.

Case 95.-Self-consciousness led to increase in double vision.

Case 96.-Emotion led to increase in unsteadiness.

Psychiatric Changes. - Various personality features of the patients before the onset of the disease were recorded above (Table III). The appearance or increase in these features after the onset of the disease are recorded in Table VII.

There is no significant difference in the trends shown by the patients with disseminated sclerosis and the control patients. In particular, hysteria was less frequent in the patients with disseminated sclerosis (twice) than in the control group (three times). Only four patients (three with disseminated sclerosis, one a control), noted a tendency for a feature to decrease or disappear. One of these patients was interviewed at the age of 50, 20 years after the onset of disseminated sclerosis. She gave a history of performing obsessional rituals since childhood. At the age of 45 she attended an unqualified lay "psychologist", who gave her homely talks over a period of two years, during which time she lost her obsessional personality and neurosis. It is debatable whether this cure is to be ascribed to psychotherapy or to progressive organic disease of the brain. The relief of obsessional neurosis by prefrontal leucotomy suggests that a plaque of disseminated sclerosis interrupting frontothalamic tracts might result in a cure of this nature. A similar instance has been recorded by Braceland and Giffin (1950).

The patients in this series have been followed for too short a period to provide a reliable estimate of the incidence of psychosis in patients with disseminated sclerosis. A larger number of patients with disseminated sclerosis was therefore studied; 544 patients last seen or traced in the years 1948 to 1950 had been followed for a total of 2,097 observation years. Of these patients, two were admitted to a mental hospital as certified patients :

TABLE VII

CHANGES, AFTER ONSET OF ILLNESS, IN FEATURES RECORDED IN TABLE III

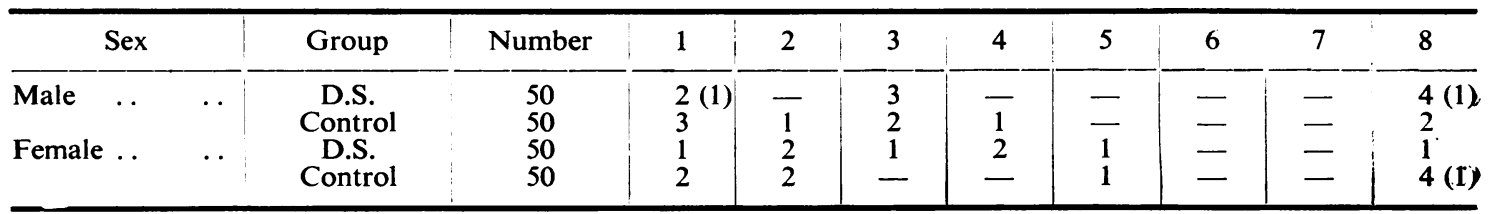

Columns 1 to 8 as for Table III. Number of patients with feature appearing for first time. Additional numbers in brackets record patients in whom the feature, previously present .increased. 
No. 77 of this series, a hysterical psychopath, was admitted to a mental hospital under certificate because of aggressive behaviour; she was discharged however within a week.

L.T. Onset 33 ; aged 50 he became aurally and visually hallucinated, with delusions of persecution. He was admitted to a mental hospital under certificate because of occasional impulsive attacks.

The chances of a person in the third to sixth decades being admitted as a certified patient to a mental hospital in any one year for the first time is about 1, 1,700 excluding patients, such as No. 77 above, discharged shortly after admission, (Slater, 1934-1935). The observed incidence amongst patients with disseminated sclerosis of admission to a mental hospital as a certified patient $(1 / 2,097)$ is therefore lower than the incidence in the general population. No adequate figures for a control population are available to assess the incidence of psychosis not leading to certification.

Emotional Changes.-Specific inquiry (based on the questionnaire of Cottrell and Wilson, 1926) was made of each patient of changes since the onset of the illness in mood, in lability of affect, in control of emotional expression, and in bodily feeling. The number of patients who admitted to such changes, and the number of patients with impaired control over emotional expression which was not evident to themselves, are recorded in Table VIII.
The following significant differences were noted : an increase in cheerfulness of mood since the onset of the illness was noted by seven patients with disseminated sclerosis, and by no control patient (exact $\chi^{2}$ gave $\mathrm{p}=0.007$, a significant difference). A tendency to laugh more easily was admitted by six patients with disseminated sclerosis and by no control patient (exact $\chi^{2}$ gave $p=0.014$, a significant difference). A tendency to laugh too easily, not admitted by the patient, was noted in 16 patients with disseminated sclerosis and in one control patient $(\chi=3 \cdot 8)$. A tendency to cry more easily was admitted by 29 patients with disseminated sclerosis and by 17 control patients $(\%=2 \cdot 0)$.

The number (six) of patients with disseminated sclerosis who stated that after the onset of the disease they had an increase in bodily well-being at rest was greater than the number (two) of control patients, but the difference did not reach a significant level.

Intellectual Changes.-Three findings relevant to the assessment of intellectual impairment were noted (Table IX), namely a complaint of failing memory, a clinical impression of intellectual impairment, and a conceptual quotient below 70 (with a vocabulary score of 24 or above) on the Shipley (1940) Hartford Scale. The estimated incidence of impairment varied with each method of assessment from $15 \%$ to $28 \%$. Of the three

TABLE VIII

EMOTIONAL CHANGES SINCE ONSET

\begin{tabular}{|c|c|c|c|c|c|c|c|c|c|c|c|c|c|c|c|}
\hline Sex and Group & 1 & 2 & 3 & 4 & 5 & 6 & 7 & 8 & 9 & 10 & 11 & 12 & 13 & 14 & $8+13$ \\
\hline $\begin{array}{ll}\text { Male : } & \text { D.S. } \\
\text { Female : } & \text { Control... } \\
& \text { D.S. Control... }\end{array}$ & $\begin{array}{l}20 \\
21 \\
25 \\
23\end{array}$ & $\frac{3}{4}$ & $\frac{-}{2}$ & $\begin{array}{l}2 \\
4 \\
6 \\
8\end{array}$ & $\begin{array}{r}12 \\
11 \\
15 \\
9\end{array}$ & $\begin{array}{l}1 \\
1 \\
1 \\
\end{array}$ & - & $\begin{array}{c}5 \\
-- \\
-\end{array}$ & $\begin{array}{c}- \\
2 \\
3\end{array}$ & $\begin{array}{r}15 \\
6 \\
14 \\
11\end{array}$ & $\begin{array}{l}3 \\
1 \\
3 \\
1\end{array}$ & $\begin{array}{l}16 \\
20 \\
23 \\
24\end{array}$ & $\begin{array}{r}6 \\
1 \\
10 \\
-\end{array}$ & $\frac{1}{-}$ & $\begin{array}{r}11 \\
11 \\
11 \\
\end{array}$ \\
\hline $\begin{array}{l}\text { 1. More depressed } \\
\text { 2. More cheerful } \\
\text { 3. More easily amused } \\
\text { 4. Less easily amused }\end{array}$ & $\begin{array}{l}5 . \\
6 . \\
7 . \\
8 .\end{array}$ & $\begin{array}{l}\text { ghs } \\
\text { ghs }\end{array}$ & 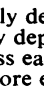 & $\begin{array}{l}\text { sed } \\
\text { ed }\end{array}$ & & $\begin{array}{l}\text { Incr } \\
\text { Dec }\end{array}$ & $\begin{array}{l}\text { less e } \\
\text { more } \\
\text { ase in } \\
\text { ease in }\end{array}$ & $\begin{array}{l}\text { ly } \\
\text { sily } \\
\text { dily } \\
\text { odily }\end{array}$ & be & & $\begin{array}{l}13 . \\
14 .\end{array}$ & cti & Dos & $\begin{array}{l}\text { tion, } \\
\text { itted } \\
\text { tion }\end{array}$ & $\begin{array}{l}\text { ughs toc } \\
\text { patient } \\
\text { paties toc } \\
\text { patient }\end{array}$ \\
\hline
\end{tabular}

TABLE IX

NUMBER OF PATIENTS WITH INTELLECTUAL IMPAIRMENT

\begin{tabular}{|c|c|c|c|c|c|c|}
\hline \multirow{2}{*}{\multicolumn{2}{|c|}{ Sex and Group }} & & \multirow{2}{*}{$\begin{array}{c}\text { Complaint of Failing } \\
\text { Memory. (Number } \\
\text { at risk : } 50)\end{array}$} & \multirow{2}{*}{$\begin{array}{l}\text { Clinical Impression of } \\
\text { Intellectual Impairment } \\
\text { (No. at risk : 50) }\end{array}$} & \multicolumn{2}{|c|}{$\begin{array}{l}\text { C.Q. below } 70 \text { in those } \\
\text { with Vocabulary Score of } \\
24 \text { or above on Shipley- } \\
\text { Hartford Test }\end{array}$} \\
\hline & & & & & & $\begin{array}{l}\text { No. at } \\
\text { Risk }\end{array}$ \\
\hline
\end{tabular}


methods of assessment, only the clinical impression of intellectual impairment was associated with a severe degree of physical disability, and this association did not quite reach the level of significance $(\chi=1 \cdot 7)$.

The association of the following emotional changes after the onset of the disease with intellectual impairment as estimated above was studied : increase in cheerfulness; increase in bodily well-being; increase in ease of laughter admitted by patient; increase in ease of laughter not admitted by patient.

The following significant associations were found. Increase in ease of laughter not admitted by the patient was associated with a clinical impression of intellectual deterioration $(\chi=2 \cdot 7)$. Increase in ease of laughter, whether noted by the patient or the interviewer, was associated with a clinical impression of intellectual deterioration $(\chi=3 \cdot 2)$, and with a severe degree of neurological disability $(\%=2 \cdot 5)$.

The clinical assessment of intellectual impairment depends in part on the appraisal of defects in judgment, as shown, for example, by the presence of undue or inappropriate laughter (Davies, 1949), and in the absence of a valid objective assessment of intellectual deterioration it cannot be concluded from these figures that the two features are necessarily interdependent.

A further investigation of intellectual impairment was made in an unselected series of 64 inpatients suffering from disseminated sclerosis, largely outside the present series (Appendix I). In addition seven female patients in a hospital for the chronic sick were tested; these were selected as the most cooperative and least disabled in the hospital. Two tests were done by each patient, the Mill Hill vocabulary (synonyms, set $\mathrm{B}$ ), and the progressive matrices 1938. The progressive matrices test is intended to assess " a person's present capacity for intellectual activity, whatever his education may be", and the vocabulary test to assess " the fund of information he has acquired as a result of intellectual activity in the past" (Raven, 1950). Patients with intellectual impairment from organic disease of the brain tend to have relatively lower scores on the progressive matrices test than on the vocabulary scale. From the scores on the two tests each patient was placed in the centile appropriate to his score and age; these were then expressed as average standard scores over the centiles 1 to 5 , 6 to 25,26 to 50,51 to 75,76 to 95,96 to 100 , in order to make the scores additive. From the difference of the standard scores of each patient the performance on each test could be compared. The mean difference between mild and moderate cases on the one hand, and severe cases on the other hand, of the difference between the average standard scores on each test was 0.809 (S.E. \pm $0 \cdot 359$ ). There was therefore a significant difference in performance between mild and moderate cases on the one hand and severe cases on the other hand. The performance of severe cases was relatively impaired on the progressive matrices test, a finding which indicates intellectual impairment in that group.

\section{Discussion}

There are several causes for the discrepancies of opinion between authors who have investigated various psychiatric aspects of disseminated sclerosis. All psychiatric assessment has a large subjective variation. The diverse connotations given to certain terms (for example " euphoria") make comparison difficult between any two series. The incidence of severity of neurological disability differs in various series, leading to variations in the frequency with which changes in personality following the illness are found. Finally in the frequent absence of any control series of patients the significance of the reported findings remains in doubt.

Premorbid Personality.-Most authors do not recognize a specific premorbid personality type in patients suffering from disseminated sclerosis. Those who find a hysterical personality appear to be dealing with a selected group, in that the patients described have submitted to prolonged psychotherapy or psychoanalysis. In this series hysterical manifestations before the onset of the disease were found less frequently in the patients with disseminated sclerosis than in the control series. The slightly higher incidence of a worrying temperament in the patients with disseminated sclerosis indicates that they do not regard themselves as " happy-golucky" (Grinker, Ham, and Robbins, 1950). In this series there was no difference in the distribution of the patients with disseminated sclerosis and the control series between the varieties of personality in the schemes chosen for classification (those of Jung and Sheldon), nor did any characteristic type of personality emerge from the group of patients with disseminated sclerosis. The use of the Thematic Apperception Test in a small group of patients did not suggest an undue incidence of suppressed aggression, which has been considered to play a part in the genesis of certain psychosomatic disorders.

Emotional Antecedents. - The factor of emotional stress in the genesis of the onset or relapse of disseminated sclerosis has been mentioned by many authors. However, those authors (Braceland and Giffin, 1950) who also studied a control series did 
not consider that psychological trauma played a part, and Brickner and Simons (1950) noted that many patients were unaffected by emotional stress. In the present series, 38 patients with disseminated sclerosis and 26 of the control series admitted an emotional stress in the month preceding the onset of symptoms; the difference between the proportions, however, does not quite reach a level of significance $(\chi=1 \cdot 8)$. In most instances the emotional stress was not of undue degree or significance, and many patients appeared to be unaffected by similar or more severe stress. The number of instances $(25 \%)$ of emotional disturbance antedating relapses in patients with disseminated sclerosis is very similar to that obtained $(26 \%)$ for the onset of the disease in control patients. Nevertheless, even allowing for chance coincidence and the tendency for positive rather than negative associations to be reported, there are many striking instances of emotional stress antedating the onset or relapse of disseminated sclerosis. As Claude Bernard (1927) remarked on puncture diabetes : " negative facts when considered alone never teach us anything" ; in a few instances emotional stress appears to have precipitated the onset or relapse of disseminated sclerosis. The finding of a significant tendency in patients with disseminated sclerosis for emotional stress to cause a transient exacerbation of symptoms due to a pre-existing lesion, possibly by way of a vascular mechanism, suggests that in certain patients (for example in the last case given above, "H.B.") short-lived disturbance of function may lead to a more lasting structural change.

Psychiatric Changes Following the Illness.Estimates of the degree of anxiety in patients suffering from disseminated sclerosis differ widely (Ombredane, 1929; Harrower, 1950). In this series the number of patients with disseminated sclerosis who developed a worrying temperament did not suffer significantly from the number in the control series. Hysterical manifestations following the onset of the illness were less frequent in patients with disseminated sclerosis than in the control series. It is concluded that neither anxiety nor hysteria is a characteristic feature of patients with disseminated sclerosis. The disappearance of a long-standing obsessional neurosis in a patient with disseminated sclerosis suggests that a plaque of disseminated sclerosis interrupting fronto-thalamic tracts might produce an anatomical and functional change similar to that following pre-frontal leucotomy.

The incidence of disseminated sclerosis in patients of mental hospitals is no higher than in the general population (Howes, 1927). A follow-up investi- gation of a larger series of 544 patients with disseminated sclerosis revealed a lower incidence of certification than that expected in the general population of a similar age-group. However, two factors tend to lower the incidence of certification in patients with disseminated sclerosis. First, they may be unable from physical disability to commit actions leading to certification. Secondly a degree of dementia which in a physically fit person would require certification will probably in a patient with disseminated sclerosis be accompanied by a degree of physical disability determining admission to a hospital for the chronic sick rather than to a mental hospital.

Emotional Changes following the Illness.Euphoria, defined in terms as discrepant as " cheerfulness" and " unconcern", has been accepted as a characteristic feature of disseminated sclerosis, in a widely varying percentage of patients. The discordant findings of Cottrell and Wilson (1926), and of Braceland and Giffin (1950) in a series containing many patients in common, have been mentioned above. In the present series an increase in cheerfulness since the onset of the disease was admitted by seven patients with disseminated sclerosis and by no control patient. Impaired control over the expression of laughter and of crying was found to be a significant feature of the patients with disseminated sclerosis; the former was associated with the clinical impression of intellectual impairment, and with a severe degree of neurological disability. An increase in eutonia since the onset of the disease was admitted by six patients with disseminated sclerosis and by two of the control series.

Intellectual Changes following the Illness.Intellectual impairment was found by Canter (1951) in 23 patients on repeating an intelligence test (the American Army General Classification Test), initially given before the onset of the disease, after an average lapse of four years. He found impairment on the Wechsler-Bellevue test in 47 patients after the onset of the disease over as short a period as six months. Four indirect tests of intellectual impairment, depending on a discrepancy between performance on a vocabulary test and on a variety of other tests, also indicated the presence of intellectual impairment. In the present series intellectual impairment, variously assessed by a complaint of failing memory, by clinical judgment, and by the Shipley Hartford test, was present in from $15 \%$ to $28 \%$ of patients. In an additional investigation, 71 inpatients, largely outside the present series, were given two tests, the Mill Hill vocabulary synonyms set $B$, and the progressive 
matrices, 1938. The performance of patients with a severe degree of neurological disability, as compared with those with mild and moderate degrees, was relatively impaired on the Progressive Matrices Test, indicating the presence of intellectual impairment in that group.

\section{Summary}

The findings in a selection of previous reports on various psychiatric aspects of disseminated sclerosis are reviewed. The causes of the discrepancies between these findings are considered.

An investigation was made of 100 patients with disseminated sclerosis and of 100 control patients attending a department for nervous diseases, with regard to premorbid personality, emotional antecedents of the illness, and psychiatric emotional and intellectual changes following the illness.

No specific premorbid personality type was defined in patients suffering from disseminated sclerosis.

Emotional stress antedating the onset or relapse of disseminated sclerosis was considered to be occasionally of significance.

A significant number of patients with disseminated sclerosis stated that an emotional stress, often of a specific nature, led invariably within the lapse of a minute to an exacerbation of symptoms due to a pre-existing lesion.

Anxiety, hysteria, and psychosis were found not to be features of disseminated sclerosis.

Emotional lability and intellectual impairment were found in a significant proportion of patients with disseminated sclerosis, especially in those with marked neurological disability.

My thanks are due to Dr. Douglas McAlpine, physician in charge of the department for nervous diseases, Middlesex Hospital, who was responsible for the initiation and guidance of this investigation. Professor L. S. Penrose gave invaluable advice on the treatment of the results of this study. To Dr. N. D. Compston and to Dr. W. A. Ll. Bowen I am indebted for many critical comments. Miss D. J. Kinloch Beck, Dr. Michael Kremer, and Dr. W. H. A. Pratt kindly allowed me to interview patients under their care.
A part of this work was carried out during the tenure of a Comyns Berkeley Fellowship from The Middlesex Hospital Medical School.

\section{REFERENCES}

Barbellion, W. N. P. pseud. Cummings, B. F. (1948). "The Journal of a Disappointed Man". Harmondsworth, Middlesex (Penguin Books).

Bernard, Claude (1927). "An Introduction to the Study of Experimental Medicine". (English translation). New York.

Borberg, N. C., and Zahle, V. (1946). Acta psychiat. Kbh., 21, 75.

Braceland, F. J., and Giffin, M. E. (1950). Proc. Assnc. Res. Nerv. and Ment. Dis., 28, 450.

Brain, W. Russell (1930). Quart. J. Med., 23, 343.

Brickner, R. M. (1950). Proc. Assoc. Res. Nerv. and Ment. Dis., 28, 466.

- - , and Simons, D. J. (1950). Ibid., 28, 143.

Brown, S., and Davis, T. K. (1922). Arch. Neurol. Psychiat., (Chicago), 7, 629.

Canter, A. H. (1951). J. gen. Psychol., 44, 3, 27.

Charcot, J. M. (1877). Lectures on the Diseases of the Nervous System. Trans. G. Sigerson. London.

Cottrell, S. S., and Wilson, S. A. K. (1926). J. Neurol Psychopath., 7, 1.

Davies, D. L. (1949). Journal of Neurology, Neuro surgery, and Psychiatry, $12,34$.

Firth, D. (1948). "The Case of Augustus d'Este". Cambridge.

Grinker, R. R., Ham, G. C., and Robbins, F. P. (1950). Proc. Assoc. Res. Nerv. and Ment. Dis., 28, 456.

Harrower, M. R. (1950). Ibid., 28, 461.

Howes, S. F. H. (1927). Boston med. surg. J., 196, 310.

Jung, C. G. (1928). Two Esaays on Analytical Psychology. Trans H. G. and C. F. Baynes. London.

Langworthy, O. R. (1950). Proc. Assoc. Res. Nerv. and Ment. Dis., 28, 598.

- Kolb, L. C., and Androp, S. (1941). Amer. J. Psychiat., 98, 243.

McAlpine, D. (1946). Brain, 69, 233.

Mackay, R. P. (1950). Proc. Assoc. Res. Nerv. and Ment. Dis., 28, 468.

Moxon, W. (1875). Guy's Hosp. Rep., 3rd Series, 20, 437.

Murray, H. A. (1943). "Thematic Apperception Test". Cambridge, Massachusetts.

Ombredane, A. (1929). "Les Troubles Mentaux de la Sclerose en Plaques", Paris.

Raven, J. C. (1950). " Progressive Matrices (1938) and The Mill Hill Vocabulary Scale ". London.

Sheldon, W. H., Hartl, E. M., and McDermott, E. (1949). "Varieties of Delinquent Youth". New York. Shipley, W. C. (1940). J. Psychol., 9, 371.

Slater, E. (1934-5). Ann. Eugen. Lond., 6, 172.

Wilson, S. A. K. (1940). Neurology, vol. 1. London. 


\section{A P P E N D I X \\ TABLE I}

DISTRIBUTION OF SCORES ON MILL HILL VOCABULARY AND PROGRESSIVE MATRICES TEST

\begin{tabular}{|c|c|c|c|c|c|c|c|c|c|c|}
\hline \multirow[b]{2}{*}{ Source } & \multirow[b]{2}{*}{ Sex } & \multirow{2}{*}{$\begin{array}{l}\text { Degree of } \\
\text { Disability }\end{array}$} & \multirow{2}{*}{$\begin{array}{c}\text { Number } \\
\text { in } \\
\text { Group }\end{array}$} & \multirow[b]{2}{*}{ Test } & \multicolumn{6}{|c|}{ Centile Group and Corresponding Average Standard Score } \\
\hline & & & & & $\begin{array}{c}1-5 \\
-2 \cdot 062 \sigma\end{array}$ & $\begin{array}{c}6-25 \\
-1 \cdot 073 \sigma\end{array}$ & $\begin{array}{c}26-50 \\
-0.324 \sigma\end{array}$ & $\begin{array}{c}51-75 \\
+0 \cdot 324 \sigma\end{array}$ & $\begin{array}{c}76-95 \\
+1.073 \sigma\end{array}$ & $\begin{array}{r}96-100 \\
+2.062 \sigma\end{array}$ \\
\hline M.H. & M. & 1 and 2 & 15 & Mill Hill & - & - & 4 & 4 & 4 & 3 \\
\hline M.H. & M. & 3 & 7 & Mill Hill & - & - & 2 & 1 & 3 & 1 \\
\hline M.H. & M. & 1 and 2 & 15 & $\begin{array}{l}\text { Progressive } \\
\text { Matrices }\end{array}$ & - & - & 1 & 1 & 8 & 5 \\
\hline M.H. & M. & 3 & 7 & $\begin{array}{l}\text { Progressive } \\
\text { Matrices }\end{array}$ & 1 & - & 1 & 2 & 3 & - \\
\hline М.H. & F. & 1 and 2 & 33 & Mill Hill & 一 & 3 & 9 & 6 & 8 & 7 \\
\hline М.H. & F. & 3 & 9 & Mill Hill & - & 1 & 2 & 3 & 3 & - \\
\hline M.H. & F. & 1 and 2 & 33 & $\begin{array}{c}\text { Progressive } \\
\text { Matrices }\end{array}$ & - & 1 & 4 & 7 & 12 & 9 \\
\hline M.H. & F. & 3 & 9 & $\begin{array}{l}\text { Progressive } \\
\text { Matrices }\end{array}$ & - & 1 & - & 3 & 4 & 1 \\
\hline C.S. & F. & 3 & 7 & Mill Hill & - & 2 & 1 & 2 & 2 & - \\
\hline C.S.* & F. & 3 & 7 & $\begin{array}{c}\text { Progressive } \\
\text { Matrices }\end{array}$ & 4 & 1 & 1 & - & 1 & - \\
\hline
\end{tabular}

C.S. $=$ Hospital for Chronic Sick M.H. $=$ Middlesex Hospital

TABLE II

SUM AND AVERAGE OF STANDARD SCORES

\begin{tabular}{|c|c|c|c|c|c|c|c|}
\hline 1 & 2 & 3 & 4 & 5 & 6 & 7 & 8 \\
\hline Source of Patients & Sex & $\begin{array}{l}\text { Degree of } \\
\text { Disability }\end{array}$ & $\begin{array}{c}\text { Number } \\
\text { in } \\
\text { Group }\end{array}$ & $\begin{array}{c}\text { Sum of Standard } \\
\text { Scores on Mill } \\
\text { Hill Vocabulary } \\
\text { Test }\end{array}$ & $\frac{5}{4}$ & $\begin{array}{l}\text { Sum of Standard } \\
\text { Scores on } \\
\text { Progressive } \\
\text { Matrices }\end{array}$ & $\begin{array}{l}7 \\
4\end{array}$ \\
\hline Middlesex Hospital & M. & All & 22 & $+15 \cdot 435$ & +0.702 & $+20 \cdot 275$ & +0.922 \\
\hline Middlesex Hospital & F. & All & 42 & $+21 \cdot 297$ & +0.507 & $+37 \cdot 586$ & +0.895 \\
\hline Hospital for Chronic Sick & F. & Severe & 7 & $+0 \cdot 324$ & +0.046 & $-8 \cdot 572$ & $-1 \cdot 224$ \\
\hline
\end{tabular}

TABLE III

COMPARISON OF DIFFERENCES BETWEEN AVERAGE STANDARD SCORES

\begin{tabular}{|c|c|c|c|c|c|c|}
\hline Source of Patients & & Sex & $\begin{array}{l}\text { Degree of } \\
\text { Disability }\end{array}$ & $\begin{array}{l}\text { Number } \\
\text { in } \\
\text { Group }\end{array}$ & $\begin{array}{l}\text { Sum of Standard Scores } \\
\text { on Vocabulary Test } \\
\text { Minus Sum of Scores on } \\
\text { Progressive Matrices }\end{array}$ & $\frac{5}{4}$ \\
\hline Middlesex Hospital. . & $\cdots$ & M. & Mild and moderate & 15 & $-8 \cdot 416$ & -0.561 \\
\hline Middlesex Hospital. . & . & M. & Severe & 7 & $+3 \cdot 476$ & +0.496 \\
\hline Middlesex Hospital. . & . & F. & Mild and moderate & 33 & $-12 \cdot 506$ & $-\mathbf{0} \cdot 379$ \\
\hline Middlesex Hospital. . & . & F. & Severe & 9 & $-3 \cdot 783$ & -0.420 \\
\hline Hospita! for Chronic Sick & . & $\mathrm{F}$. & Severe & 7 & $+8 \cdot 896$ & $+1 \cdot 271$ \\
\hline All sources $\ldots \quad \ldots$ & . & M. and F. & Mild and moderate & 48 & $-20 \cdot 922$ & -0.436 \\
\hline All sources .. $\quad$. & . & M. and F. & Severe & 23 & $+8 \cdot 589$ & +0.373 \\
\hline
\end{tabular}

Difference (column 6) between mild and moderate cases on the one hand and severe cases on the other $=+0.809$.

$\mathrm{SE}=\sqrt{\frac{2}{\mathrm{n}_{1}}+\frac{2}{\mathrm{n}_{2}}}=\therefore \mathbf{0 . 3 5 9}$ 